\title{
Postendarterectomy Mortality in Octogenarians and Nonagenarians in the USA from 1993 to 1999
}

\author{
Judith H. Lichtman ${ }^{a}$ Sara B. Jones ${ }^{a} \quad$ Yun Wang $^{\text {a }}$ Emi Watanabe ${ }^{a}$ \\ Norrina B. Allen ${ }^{a}$ Pierre Fayad $^{b}$ Larry B. Goldstein ${ }^{c}$ \\ aSection of Chronic Disease Epidemiology, Department of Epidemiology and Public Health, Yale University School \\ of Medicine, New Haven, Conn., ${ }^{b}$ Department of Neurological Sciences, University of Nebraska Medical Center, \\ Omaha, Nebr., and ${ }^{\mathrm{C}}$ Department of Medicine (Neurology), Duke Stroke Center, Center for Clinical Health Policy \\ Research, Duke University and Durham VAMC, Durham, N.C., USA
}

\section{Key Words}

Carotid endarterectomy $\cdot$ Mortality $\cdot$ Octogenarians $\cdot$

Nonagenarians

\begin{abstract}
Background: Relatively little is known about trends in the utilization or outcomes of carotid endarterectomy (CEA) in the very elderly. We determined trends in the rates of CEA and perioperative (in-hospital and 30-day) and long-term $(1-, 2-, 3-, 4-$ and 5-year) mortality in a US national sample of patients $\geq 80$ years of age. Methods: All fee-for-service Medicare patients ( $80-89$ and $\geq 90$ years of age) who had a CEA [ICD-9-CM (International Classification of Diseases, Ninth Revision, Clinical Modification): 38.12] from 1993 to 1999 were identified using the Centers for Medicare and Medicaid Services Inpatient Standard Analytic Files. Demographic characteristics and comorbid conditions were determined using ICD-9-CM diagnostic codes within the year prior to the index hospitalization for CEA. Results: A total of 140,376 CEA were performed in patients aged $80-89$ years and 6,446 in those aged $\geq 90$ years during this 7 -year period. The annual number of operations increased from 13,115 in 1993 to 21,582 in 1999 for octogenarians, and from 481 in 1993 to 1,257 in 1999 for nonagenarians. Perioperative mortality was $2.2 \%$ in octogenarians and $3.3 \%$ in nonagenarians.
\end{abstract}

Long-term mortality increased by approximately $10 \%$ per year after the operation, and was $43 \%$ in octogenarians and $56 \%$ in nonagenarians at 5 years. Perioperative mortality rates remained relatively stable over the 7-year period for both age groups although comorbidities increased. Conclusions: The number of CEA performed in the very elderly in the USA increased from 1993 to 1999. Perioperative mortality rates were high compared with trial results, while longterm survivorship was comparable to that of similarly-aged peers in the USA.

Copyright $\odot 2009$ S. Karger AG, Basel

\section{Introduction}

Randomized controlled trials have demonstrated the efficacy of carotid endarterectomy (CEA) for the treatment of patients with symptomatic and asymptomatic carotid artery disease [1-8]. These trials have, however, excluded or included only small numbers of very elderly patients, providing limited evidence about the effectiveness of the operation for these patients [9]. This represents an important gap because stroke is the second leading cause of death in individuals aged 85 and over [10] who, by 2050 , will number approximately 20.9 million in the USA [11]. The proportion of CEA recipients aged 80

\section{KARGER}

(C) 2009 S. Karger AG, Basel

Fax +4161306 1234 E-Mail karger@karger.ch www.karger.com
Accessible online at: www.karger.com/ced
Judith H. Lichtman, PhD, MPH

Yale University School of Medicine

PO Box 208034

New Haven, CT 06520-8034 (USA)

Tel. +1 203785 3025, Fax +1 203785 6980,E-Mail judith.lichtman@yale.edu 
years and above increased during the 1990s [12-17], but secular trends in utilization and mortality for the very elderly are not well described.

Octogenarians who undergo CEA have 30-day mortality rates ranging from 0 to $3.6 \%[14-16,18-33]$. The 5 year mortality rate for patients $>80$ years of age is estimated between 25 and 55\%, based on data from 3 international and 1 US study, each with fewer than 200 patients $[14,15,19,20]$. Thirty-day mortality rates in nonagenarians range from 0 to $6.3 \%$ with a 2 -year mortality of $15 \%$ [34-36]. These estimates are based on studies with small numbers of patients drawn from single hospitals, statewide samples or small surgical groups.

To provide a US national perspective on CEA trends and outcomes in very elderly patients, we determined CEA utilization rates, length of hospitalization, perioperative (in-hospital and 30-day) and long-term (1-, 2-, 3-, 4- and 5-year) mortality for all fee-for-service (FFS) Medicare beneficiaries aged 80 years or older who had a CEA between 1993 and 1999.

\section{Methods}

Eligible FFS Medicare beneficiaries aged $\geq 80$ years were identified for each calendar year from 1993 through 1999, using the Centers for Medicare and Medicaid Services Inpatient Standard Analytic Files and the ICD-9-CM (International Classification of Diseases, Ninth Revision, Clinical Modification) code for CEA (ICD-9-CM: 38.12). Mortality was determined from the Medicare Enrollment Database and the National Death Index. The accuracy of the ascertainment of vital status using these data resources is $>95 \%$ for subjects aged $\geq 85$ years [37].

Demographic characteristics including age, sex and race-ethnicity were obtained from Medicare inpatient data. The medical history and comorbid conditions [history of stroke, acute myocardial infarction (AMI), congestive heart failure (CHF), diabetes, hypertension, renal disease, chronic obstructive pulmonary disease (COPD), dementia and cancer], the number of hospitalizations in the prior year (dichotomized as $\geq 2$ or $<2$ ) and the Deyo comorbidity index [38] (dichotomized as $\geq 3$ or $<3$ conditions) were determined based on ICD-9-CM diagnostic codes within the 12 months before the index hospitalization for CEA. We identified comorbidities in the year prior to the index hospitalization to avoid misclassifying pre-existing comorbid conditions as complications during the hospitalization. The hospital length of stay (LOS) was calculated based on the difference in the dates of discharge and admission plus 1 day. A value of 1 day was assigned to patients who were admitted and discharged on the same day. The discharge disposition (home, skilled nursing facility, in-hospital death or other) was reported from the index hospitalization. The all-cause perioperative (in-hospital and 30-day) and long-term (1-, 2-, 3-, 4- and 5-year) mortality were calculated from the date of hospital admission. Trends in baseline demographic and clinical characteristics of patients across calendar years were assessed within age groups, using the Mantel-extension $\chi^{2}$ test for categorical variables and the Kruskal-Wallis test for continuous variables. To examine secular trends in CEA utilization, we developed Poisson regression models to compare the age-specific incidence rate of CEA utilization with the age-specific rate of population growth. Analyses were conducted using SAS Version 9.1.3 (SAS Institute Inc., Cary, N.C., USA).

\section{Results}

A total of 140,376 Medicare beneficiaries $80-89$ years of age and 6,446 beneficiaries 90 years of age or older had a CEA between 1993 and 1999. For octogenarians, there was an increase in the number of CEAs from 13,115 in 1993 to 21,582 in 1999 (fig. 1). This increase occurred predominantly from 1993 to 1995 , after which the number of operations remained relatively constant. Among nonagenarians, the number of CEAs increased steadily from 481 in 1993 to 1,257 in 1999. The observed rate of CEA growth was greater than the population growth over this time interval for both age groups.

Demographic characteristics remained relatively stable over time for octogenarians and nonagenarians (tables 1,2). Among the octogenarians, there were increases in the prevalence rates of AMI (8.5-13.0\%), CHF (7.08.1\%), diabetes (14.5-18.8\%), hypertension (46.9-61.1\%) and COPD (16.4-18.2\%). Among the nonagenarians, there were increases in the prevalence rates of stroke (1.02.0\%), AMI (6.9-11.9\%), CHF (5.8-10.4\%), diabetes (11.2$12.9 \%)$ and hypertension (43.7-58.8\%). The LOS decreased for the octogenarians $(6.7 \pm 6.4$ to $4.1 \pm 4.7$ days) and nonagenarians ( $8.1 \pm 7.3$ to $4.8 \pm 5.1$ days $)$ (fig. 2). The discharge location remained relatively constant for both age groups, with approximately $80 \%$ of the octogenarians discharged home compared with $68 \%$ of the nonagenarians.

In-hospital mortality was $1.5 \%$ for the octogenarians, and the 30 -day mortality was $2.2 \%$ (fig. 3 ). The perioperative mortality rates for the nonagenarians were similar to those for the octogenarians (2.1\% in-hospital mortality and $3.3 \%$ 30-day mortality). For the octogenarians, the mortality rates were $10.7,20.0,27.6,35.6$ and $43.3 \%$ at 1 , 2, 3, 4 and 5 years, respectively (fig. 3). The nonagenarians had mortality rates of $16.5,28.3,38.3,47.3$ and $56.2 \%$ at 1,2,3, 4 and 5 years, respectively. The long-term mortality rates remained relatively stable for both age groups over time (fig. 4). Perioperative mortality fluctuated somewhat for the nonagenarians, with in-hospital mortality ranging from 1.4 to $3.5 \%$, and 30 -day mortality ranging from 2.7 to $4.0 \%$. 

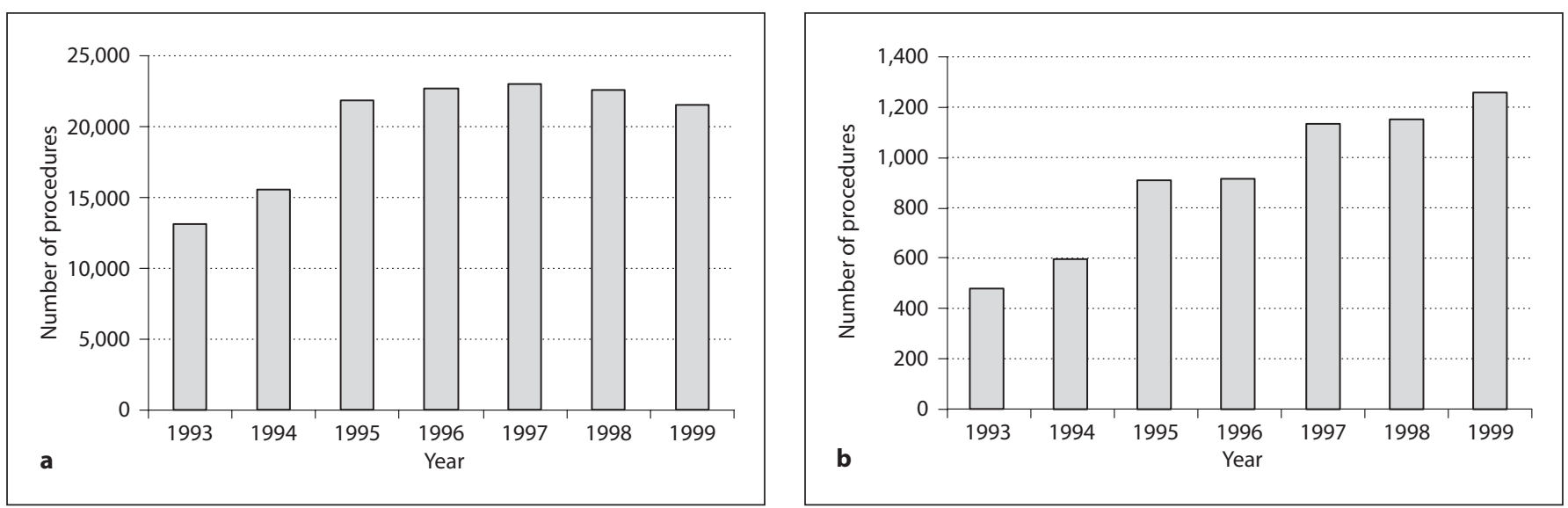

Fig. 1. CEA utilization among octogenarians (a) and nonagenarians (b) from 1993 to 1999.

Table 1. Trends in selected characteristics of octogenarians who received CEA from 1993 to 1999

\begin{tabular}{|c|c|c|c|c|c|c|c|c|}
\hline & 1993 & 1994 & 1995 & 1996 & 1997 & 1998 & 1999 & $\mathrm{p}$ \\
\hline Number & 13,115 & 15,517 & 21,857 & 22,668 & 23,024 & 22,613 & 21,582 & \\
\hline Mean age $\pm S D$, years & $82.8 \pm 2.4$ & $82.8 \pm 2.5$ & $82.9 \pm 2.5$ & $83.0 \pm 2.5$ & $83.0 \pm 2.5$ & $83.1 \pm 2.5$ & $83.5 \pm 2.5$ & $<0.0001$ \\
\hline \multicolumn{9}{|l|}{ Hospitalizations in } \\
\hline past year $\geq 2, \%$ & 12.0 & 11.2 & 11.5 & 11.4 & 12.2 & 11.8 & 12.0 & 0.0552 \\
\hline Deyo score $\geq 3, \%$ & 14.5 & 15.1 & 15.4 & 16.0 & 16.2 & 15.5 & 15.4 & 0.0207 \\
\hline \multicolumn{9}{|l|}{ Comorbidity, \% } \\
\hline Stroke & 2.2 & 2.3 & 2.2 & 2.8 & 2.8 & 2.4 & 2.5 & $<0.0001$ \\
\hline AMI & 8.5 & 9.6 & 11.1 & 11.2 & 12.1 & 12.9 & 13.0 & $<0.0001$ \\
\hline $\mathrm{CHF}$ & 7.0 & 7.2 & 7.1 & 7.7 & 8.0 & 8.1 & 8.1 & $<0.0001$ \\
\hline Diabetes & 14.5 & 15.7 & 16.5 & 17.5 & 17.8 & 17.8 & 18.8 & $<0.0001$ \\
\hline Hypertension & 46.9 & 51.7 & 55.2 & 56.9 & 58.2 & 59.5 & 61.1 & $<0.0001$ \\
\hline Renal disease & 1.9 & 2.2 & 1.6 & 1.5 & 1.5 & 1.4 & 1.3 & $<0.0001$ \\
\hline COPD & 16.4 & 17.0 & 17.4 & 18.3 & 18.7 & 18.7 & 18.2 & $<0.0001$ \\
\hline Dementia & 1.5 & 1.6 & 1.7 & 1.7 & 1.7 & 1.8 & 1.7 & 0.1489 \\
\hline Cancer & 2.2 & 2.1 & 1.9 & 1.9 & 2.0 & 1.9 & 2.0 & 0.1399 \\
\hline Discharge disposition, $\%$ & & & & & & & & $<0.0001$ \\
\hline Home & 81.0 & 81.2 & 80.5 & 79.9 & 79.2 & 80.1 & 79.2 & \\
\hline Skilled nursing facility & 5.2 & 5.0 & 5.9 & 6.1 & 7.0 & 7.0 & 6.8 & \\
\hline In-hospital death & 2.0 & 1.6 & 1.5 & 1.3 & 1.4 & 1.5 & 1.3 & \\
\hline Other & 11.9 & 12.2 & 12.1 & 12.7 & 12.5 & 11.5 & 12.6 & \\
\hline
\end{tabular}

\section{Discussion}

The absolute number of CEAs performed in very elderly Medicare beneficiaries increased from 1993 through 1999. For nonagenarians, the increase was almost 10 times greater than the increase in the number of Medicare beneficiaries in this age group. Perioperative and long-term mortality rates remained relatively stable within age groups over the 7-year period despite an increased prevalence of comorbid conditions. Octogenarians and nonagenarians had similar perioperative mortality rates, with greater differences for longer periods of follow-up. The mean length of hospitalization decreased for both age groups, whereas the discharge location remained relatively unchanged.

The increased performance of CEA in the very elderly is consistent with several studies reporting increases in the proportion of CEA recipients aged 80 or older during 

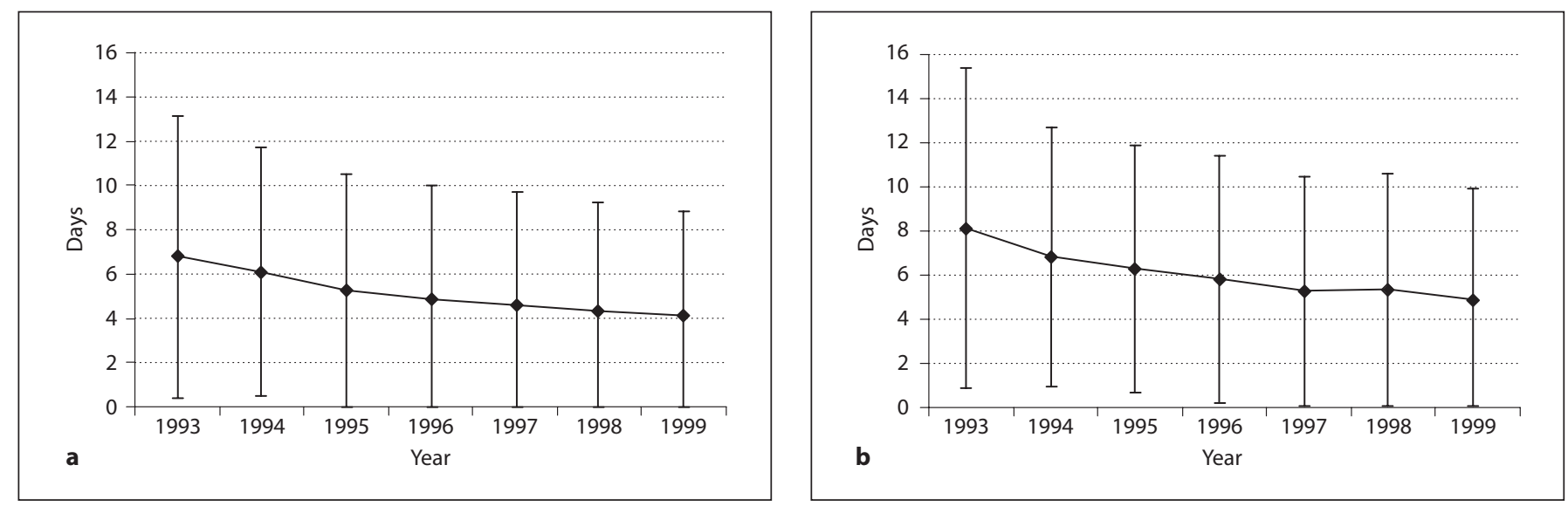

Fig. 2. LOS (means \pm SD) among octogenarians (a) and nonagenarians (b) from 1993 to 1999.

Table 2. Trends in selected characteristics of nonagenarians who received CEA from 1993 to 1999

\begin{tabular}{|c|c|c|c|c|c|c|c|c|}
\hline & 1993 & 1994 & 1995 & 1996 & 1997 & 1998 & 1999 & $\mathrm{p}$ \\
\hline Number & 481 & 595 & 907 & 918 & 1,135 & 1,153 & 1,257 & \\
\hline Mean age $\pm S D$, years & $91.6 \pm 1.9$ & $91.5 \pm 1.8$ & $91.3 \pm 1.6$ & $91.5 \pm 1.8$ & $91.4 \pm 1.7$ & $91.5 \pm 1.8$ & $91.5 \pm 1.8$ & 0.0213 \\
\hline \multicolumn{9}{|l|}{ Hospitalizations in } \\
\hline past year $\geq 2, \%$ & 7.5 & 10.1 & 10.5 & 9.9 & 11.3 & 12.2 & 13.3 & 0.0002 \\
\hline Deyo score $\geq 3, \%$ & 11.4 & 13.8 & 14.3 & 13.4 & 13.7 & 12.6 & 14.2 & 0.5071 \\
\hline \multicolumn{9}{|l|}{ Comorbidity, $\%$} \\
\hline Stroke & 1.0 & 1.2 & 1.2 & 2.7 & 2.4 & 2.1 & 2.0 & 0.0802 \\
\hline AMI & 6.9 & 8.7 & 7.7 & 9.9 & 10.0 & 12.1 & 11.9 & $<0.0001$ \\
\hline $\mathrm{CHF}$ & 5.8 & 8.9 & 8.1 & 9.0 & 8.0 & 9.1 & 10.4 & 0.0098 \\
\hline Diabetes & 11.2 & 8.4 & 10.1 & 12.1 & 10.7 & 11.5 & 12.9 & 0.0230 \\
\hline Hypertension & 43.7 & 46.1 & 51.4 & 53.6 & 57.8 & 56.3 & 58.8 & $<0.0001$ \\
\hline Renal disease & 2.3 & 2.9 & 2.4 & 2.0 & 1.8 & 0.7 & 1.4 & 0.0024 \\
\hline COPD & 14.1 & 13.5 & 13.3 & 12.8 & 13.3 & 16.1 & 14.6 & 0.2695 \\
\hline Dementia & 2.5 & 1.5 & 3.5 & 2.2 & 2.7 & 2.5 & 2.2 & 0.7259 \\
\hline Cancer & 2.3 & 2.5 & 1.4 & 2.0 & 2.5 & 2.5 & 2.5 & 0.3903 \\
\hline Discharge disposition, \% & & & & & & & & 0.9246 \\
\hline Home & 67.2 & 69.9 & 67.9 & 67.5 & 67.1 & 67.9 & 69.1 & \\
\hline Skilled nursing facility & 15.0 & 9.8 & 12.9 & 14.3 & 14.1 & 13.8 & 15.0 & \\
\hline In-hospital death & 1.9 & 3.5 & 2.1 & 1.7 & 2.3 & 2.2 & 1.4 & \\
\hline Other & 16.0 & 16.8 & 17.1 & 16.5 & 16.6 & 16.1 & 14.6 & \\
\hline
\end{tabular}

the 1990s [12-17], with a noted increase following the 1994 publication of the ACAS (Asymptomatic Carotid Atherosclerosis Study) results [13]. We found a similar increase in CEA utilization from 1994 to 1995 for both octogenarians and nonagenarians, which likely reflects an extrapolation of results of clinical trials that were carried out in younger patients. Consistent with our results, several studies found a decreased length of hospitalization over time for CEA recipients $[17,26]$.

Postendarterectomy Mortality in the Very Elderly
The perioperative mortality rate in our octogenarian sample (2.2\%) is consistent with other studies that report 30 -day mortality rates between 0 and 3.6\% [14-16, 18-25, $27-29,31,32,39,40]$. Most of these studies were of modest sample size [14-16, 18-25, 27-29, 32], included patients from single medical centers or states $[15,16,20$, $22-27,32]$, or described outcomes within a single surgical practice $[18,19]$. Only a few studies reported rates for nonagenarians. In-hospital mortality was 3.1\% among 64

Cerebrovasc Dis 2010;29:154-161 
Fig. 3. Mortality among octogenarian and nonagenarian CEA recipients from 1993 to 1999.
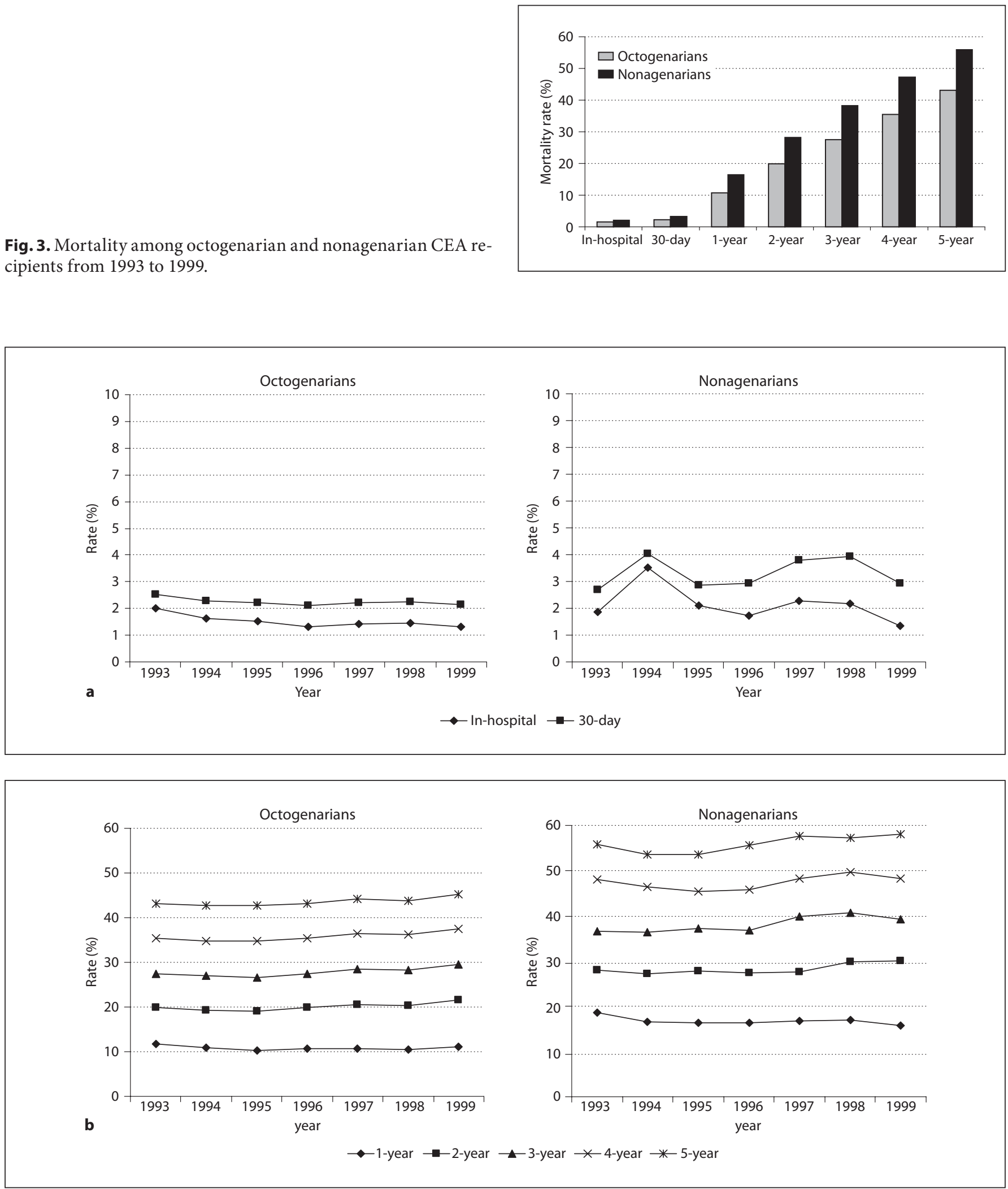

Fig. 4. Perioperative (a) and long-term (b) mortality among octogenarian and nonagenarian CEA recipients from 1993 to 1999. 
patients in one study [35], and 30-day mortality rates ranged from 0 to $6.3 \%[34,36]$ in studies of 26 and 16 patients, respectively. Many of these reports combined multiple years of data and did not describe changes over time. A study that examined in-hospital mortality trends from 1990 to 1995 among patients aged 34-92 reported no change in mortality, but the results were not stratified by age groups [26]. Our study extends these findings, demonstrating the stability of short-term mortality rates for very elderly CEA patients based on a US national sample.

For symptomatic patients, perioperative mortality rates in the 2 largest randomized trials, the ECST (European Carotid Surgery Trial) and the NASCET (North American Symptomatic Carotid Endarterectomy Trial), were 1.0 and $1.1 \%$, with perioperative stroke or death rates of 7.5 and $6.5 \%$, respectively [41]. For asymptomatic patients, the ACAS and ACST (Asymptomatic Carotid Surgery Trial) reported perioperative mortality rates of 0.1 and $1.1 \%$, with perioperative stroke or death rates of 1.5 and $3.0 \%$, respectively $[2,42]$. These trials, however, included highly selected patients and largely excluded the very elderly. Two studies using Medicare data, with additional information collected by medical chart data review, found 30-day stroke or mortality rates of $6.4-6.9 \%$ for symptomatic patients and 3.0-3.8\% for asymptomatic patients $[39,43]$. We cannot directly compare our results with clinical trials or studies with detailed clinical information (i.e., symptom status) because the indication for the operation is not included in administrative records. In addition, we could not assess perioperative stroke rates due to the limitations of administrative data. Even if we assume that all of the patients in our study were treated for symptomatic disease, our perioperative mortality rates $(2.2 \%$ for octogenarians and $3.3 \%$ for nonagenarians) are 2-3 times higher than rates reported in the clinical trials upon which the use of the operation is based. Furthermore, if we assume that nonfatal stroke or death rates are 3.5-6.5 times higher than the mortality rate in this very elderly age group $[39,41,43]$, we estimate that the rate of these outcomes could range from 7.7 to $14.3 \%$ in octogenarians and from 11.6 to $21.5 \%$ in nonagenarians. Although the rates of stroke in the very elderly with carotid stenosis who do not receive CEA may be higher than in the younger patients included in randomized trials, these estimates well exceed the $<6 \%$ perioperative complication rate for which symptomatic patients would be expected to derive a benefit from the operation [44]. Halm et al. [39] found that older age ( $\geq 80$ years) was associated with $30 \%$ higher odds of stroke or death com- pared with younger ages. We found heterogeneity in outcomes within this older age group, and the combined risk for patients $\geq 80$ years may not reflect different risks for octogenarians and nonagenarians.

Long-term mortality rates for octogenarians receiving CEA procedures in the general population have varied across studies, ranging from 7.9 to $10.5 \%$ after 1 year [14, $19,32], 10 \%$ at 2 years [19], $27 \%$ at 3 years [24], $19-41 \%$ at 4 years $[19,22,29,32,45]$ and $25-55 \%$ at 5 years $[14,15$, $19,20]$. The discrepant estimates are likely due to relatively small study samples derived from international populations $[14,19,20,24,45]$ or single US medical centers $[15,16,22,32,45]$. Our mortality rates of $10.7,20.0$, $27.7,35.6$ and $43.3 \%$ for $1-5$ years after CEA, respectively, fall within these previously reported ranges. We found that these rates remained relatively stable over time despite a concomitant increase in the prevalence of comorbid conditions, which suggests that the operation is being performed in patients with more complicated medical conditions. Limited data have been published on the long-term outcomes following CEA in nonagenarians. One study of 26 patients aged $\geq 90$ years found a $15 \% 2$ year mortality rate [36]. Data from the US National Vital Statistics Report show that the average 80 -year-old in the USA has a 5-year survival of 70\%, and the average 90 year-old has a 5 -year survival of $42 \%$ with life expectancies of 9 and 5 years, respectively [46]. This indicates that the very elderly live long enough to potentially benefit from CEA, and that the octogenarian and nonagenarian patients in our study have survivorship similar to that of their respective peers.

There are several limitations to consider in the interpretation of our study. As mentioned previously, administrative data do not provide information to assess the indication for the operation, nor is it possible to determine the chronology of events during the hospitalization (i.e., differentiate prior events from postprocedural events). The data represent FFS Medicare patients and may not be generalizable to all potential candidates for the operation in this age group; however, FFS beneficiaries represent approximately $85 \%$ of all Medicare recipients. Our data reflect treatment patterns and outcomes from 1993 through 2004 and, although treatment patterns in this population may have changed since this time, our results provide baseline data to assess whether receipt rates and outcomes have changed for these patients, particularly because comparable data are not currently available for this very elderly population. We were neither able to determine how case selection or referral patterns may influence the results, nor were we able to 
determine the cause of death. We noted that the prevalence of comorbidities in CEA recipients increased over time, while the mortality remained stable; however, we were unable to determine whether this reflects shifting demographic patterns or changing referral patterns during these years. This analysis focused on mortality, and future studies should assess long-term stroke-free survival for these very elderly patients. Finally, we were unable to assess patient-oriented outcomes such as functional status, quality of life, or neurological outcome.

Though not directly comparable, the perioperative mortality rates we found in elderly FFS Medicare beneficiaries were higher than those reported from randomized trials that excluded very elderly patients. The effectiveness of the operation needs to be evaluated in age-appropriate populations as the effect of CEA on the health sta- tus and outcomes of very elderly patients is unclear. This is an important issue, given that increasing numbers of very elderly patients are undergoing CEA.

\section{Acknowledgment}

The Centers for Medicare \& Medicaid Services reviewed and approved the use of its data for this work, and approved submission of the manuscript; this approval is based on data use only, and does not represent a Centers for Medicare \& Medicaid Services endorsement of or comment on the manuscript content. The project described was supported by grant No. R01NS 043322 from the National Institute of Neurological Disorders and Stroke. The content is solely the responsibility of the authors and does not necessarily represent the official views of the National Institute of Neurological Disorders and Stroke or the National Institutes of Health.

\section{References}

1 Beneficial effect of carotid endarterectomy in symptomatic patients with high-grade carotid stenosis. North American Symptomatic Carotid Endarterectomy Trial Collaborators. N Engl J Med 1991;325:445-453.

2 Endarterectomy for asymptomatic carotid artery stenosis. Executive Committee for the Asymptomatic Carotid Atherosclerosis Study. JAMA 1995;273:1421-1428.

-3 Randomised trial of endarterectomy for recently symptomatic carotid stenosis: final results of the MRC European Carotid Surgery Trial (ECST). Lancet 1998;351:13791387.

4 Hobson RW 2nd, Weiss DG, Fields WS, Goldstone J, Moore WS, Towne JB, Wright CB: Efficacy of carotid endarterectomy for asymptomatic carotid stenosis. The Veterans Affairs Cooperative Study Group. N Engl J Med 1993;328:221-227.

-5 Mayberg MR, Wilson SE, Yatsu F, Weiss DG, Messina L, Hershey LA, Colling C, Eskridge J, Deykin D, Winn HR: Carotid endarterectomy and prevention of cerebral ischemia in symptomatic carotid stenosis. Veterans Affairs Cooperative Studies Program 309 Trialist Group. JAMA 1991;266:3289-3294.

-6 Biller J, Feinberg WM, Castaldo JE, Whittemore AD, Harbaugh RE, Dempsey RJ, Caplan LR, Kresowik TF, Matchar DB, Toole JF, Easton JD, Adams HP Jr, Brass LM, Hobson RW 2nd, Brott TG, Sternau L: Guidelines for carotid endarterectomy: a statement for healthcare professionals from a Special Writing Group of the Stroke Council, American Heart Association. Circulation 1998;97:501509.
7 Ferguson GG, Eliasziw M, Barr HW, Clagett GP, Barnes RW, Wallace MC, Taylor DW, Haynes RB, Finan JW, Hachinski VC, Barnett HJ: The North American Symptomatic Carotid Endarterectomy Trial: surgical results in 1,415 patients. Stroke 1999;30:1751-1758.

8 Ederle J, Brown MM: Vascular intervention in stroke prevention: endarterectomy and angioplasty. Cerebrovasc Dis 2009;27(suppl 1):134-139.

\$9 Cardona P, Rubio F, Martinez-Yelamos S, Krupinski J: Endarterectomy, best medical treatment or both for stroke prevention in patients with asymptomatic carotid artery stenosis. Cerebrovasc Dis 2007;24(suppl 1): 126-133.

10 Suliman A, Greenberg J, Chandra A, Barillas S, Iranpour P, Angle N: Carotid endarterectomy as the criterion standard in high-risk elderly patients. Arch Surg 2008;143:736742, discussion 742 .

11 National Center for Health Statistics: Health, United States, 2005, with Chartbook on Trends in the Health of Americans. Hyattsville, 2005.

12 Etzioni DA, Liu JH, O’Connell JB, Maggard MA, Ko CY: Elderly patients in surgical workloads: a population-based analysis. Am Surg 2003;69:961-965.

13 Morasch MD, Parker MA, Feinglass J, Manheim LM, Pearce WH: Carotid endarterectomy: characterization of recent increases in procedure rates. J Vasc Surg 2000;31:901909.

14 Norman PE, Semmens JB, Laurvick CL, Lawrence-Brown M: Long-term relative survival in elderly patients after carotid endarterectomy: a population-based study. Stroke 2003;34:e95-e98.
15 O’Hara PJ, Hertzer NR, Mascha EJ, Beven EG, Krajewski LP, Sullivan TM: Carotid endarterectomy in octogenarians: early results and late outcome. J Vasc Surg 1998;27: 860-869, discussion 870-871.

16 Pruner G, Castellano R, Jannello AM, Astore D, Civilini E, Melissano G, Chiesa R: Carotid endarterectomy in the octogenarian: outcomes of 345 procedures performed from 1995 to 2000. Cardiovasc Surg 2003;11:105112.

17 Varghese R, Norman P: Carotid endarterectomy in octogenarians. ANZ J Surg 2004;74: 215-217.

18 Ballotta E, da Giau G, Militello C, Barbon B, de Rossi A, Meneghetti G, Baracchini C: High-grade symptomatic and asymptomatic carotid stenosis in the very elderly: a challenge for proponents of carotid angioplasty and stenting. BMC Cardiovasc Disord 2006; 6:12.

19 Cartier B: Carotid surgery in octogenarians: why not? Ann Vasc Surg 2002;16:751-755.

20 Grego F, Lepidi S, Antonello M, Bonvini S, Battocchio P, Galzignan E, Menegolo M, Segalla A, Deriu GP: Is carotid endarterectomy in octogenarians more dangerous than in younger patients? J Cardiovasc Surg (Torino) 2005;46:477-483

-21 Hobson RW 2nd, Howard VJ, Roubin GS, Brott TG, Ferguson RD, Popma JJ, Graham DL, Howard G: Carotid artery stenting is associated with increased complications in octogenarians: 30 -day stroke and death rates in the CREST lead-in phase. J Vasc Surg 2004; 40:1106-1111. 
-22 Lau D, Granke K, Olabisi R, Basson MD, Vouyouka A: Carotid endarterectomy in octogenarian veterans: does age affect outcome? A single-center experience. Am J Surg 2005;190:795-799.

-23 Maxwell JG, Taylor AJ, Maxwell BG, Brinker CC, Covington DL, Tinsley E Jr: Carotid endarterectomy in the community hospital in patients aged 80 and older. Ann Surg 2000; 231:781-788.

-24 Metz R, Teijink JA, van de Pavoordt HD, Ackerstaff RG, de Borst GJ, Kelder JC, Moll FL: Carotid endarterectomy in octogenarians with symptomatic high-grade internal carotid artery stenosis: long-term clinical and duplex follow-up. Vasc Endovascular Surg 2002;36:409-414.

-25 Miller MT, Comerota AJ, Tzilinis A, Daoud Y, Hammerling J: Carotid endarterectomy in octogenarians: does increased age indicate 'high risk'? J Vasc Surg 2005;41:231-237.

-26 Perler BA, Dardik A, Burleyson GP, Gordon TA, Williams GM: Influence of age and hospital volume on the results of carotid endarterectomy: a statewide analysis of 9,918 cases. J Vasc Surg 1998;27:25-31, discussion 31-33.

-27 Rockman CB, Jacobowitz GR, Adelman MA, Lamparello PJ, Gagne PJ, Landis R, Riles TS: The benefits of carotid endarterectomy in the octogenarian: a challenge to the results of carotid angioplasty and stenting. Ann Vasc Surg 2003;17:9-14.

28 Salameh JR, Myers JL, Mukherjee D: Carotid endarterectomy in elderly patients: low complication rate with overnight stay. Arch Surg 2002;137:1284-1287, discussion 1288.

-29 Schneider JR, Droste JS, Schindler N, Golan JF: Carotid endarterectomy in octogenarians: comparison with patient characteristics and outcomes in younger patients. J Vasc Surg 2000;31:927-935.
30 Stoner MC, Abbott WM, Wong DR, Hua HT, Lamuraglia GM, Kwolek CJ, Watkins MT, Agnihotri AK, Henderson WG, Khuri S, Cambria RP: Defining the high-risk patient for carotid endarterectomy: an analysis of the prospective National Surgical Quality Improvement Program database. J Vasc Surg 2006;43:285-295, discussion 295-296.

-31 Wennberg DE, Lucas FL, Birkmeyer JD, Bredenberg CE, Fisher ES: Variation in carotid endarterectomy mortality in the Medicare population: trial hospitals, volume, and patient characteristics. JAMA 1998;279: 1278-1281.

32 Wong DT, Ballard JL, Killeen JD: Carotid endarterectomy and abdominal aortic aneurysm repair: are these reasonable treatments for patients over age 80? Am Surg 1998;64: 998-1001.

-33 Lepore MR Jr, Sternbergh WC 3rd, Salartash $\mathrm{K}$, Tonnessen B, Money SR: Influence of NASCET/ACAS trial eligibility on outcome after carotid endarterectomy. J Vasc Surg 2001; 34:581-586.

34 Hingorani A, Ascher E, Schutzer R, Tsemkhim B, Kallakuri S, Yorkovich W, Jacob T: Carotid endarterectomy in octogenarians and nonagenarians: is it worth the effort? Acta Chir Belg 2004;104:384-387.

35 Teso D, Edwards RE, Frattini JC, Dudrick SJ, Dardik A: Safety of carotid endarterectomy in 2,443 elderly patients: lessons from nonagenarians - are we pushing the limit? J Am Coll Surg 2005;200:734-741.

36 Durward QJ, Ragnarsson TS, Reeder RF, Case JL, Hughes CA: Carotid endarterectomy in nonagenarians. Arch Surg 2005;140: 625-628, discussion 628.

37 Hill ME, Rosenwaike I: The Social Security Administration's Death Master File: the completeness of death reporting at older ages. Soc Secur Bull 2001;64:45-51.

$\checkmark 38$ Deyo RA, Cherkin DC, Ciol MA: Adapting a clinical comorbidity index for use with ICD9-CM administrative databases. J Clin Epidemiol 1992;45:613-619.

>39 Halm EA, Tuhrim S, Wang JJ, Rockman C, Riles TS, Chassin MR: Risk factors for perioperative death and stroke after carotid endarterectomy: results of the New York Carotid Artery Surgery Study. Stroke 2009;40:221229.
40 Rothwell PM: Current status of carotid endarterectomy and stenting for symptomatic carotid stenosis. Cerebrovasc Dis 2007; 24(suppl 1):116-125

41 Rothwell PM, Eliasziw M, Gutnikov SA, Fox AJ, Taylor DW, Mayberg MR, Warlow CP, Barnett HJ: Analysis of pooled data from the randomised controlled trials of endarterectomy for symptomatic carotid stenosis. Lancet 2003;361:107-116.

42 Halliday A, Mansfield A, Marro J, Peto C, Peto R, Potter J, Thomas D: Prevention of disabling and fatal strokes by successful carotid endarterectomy in patients without recent neurological symptoms: randomised controlled trial. Lancet 2004;363:14911502 .

$\checkmark 43$ Kresowik TF, Bratzler DW, Kresowik RA, Hendel ME, Grund SL, Brown KR, Nilasena DS: Multistate improvement in process and outcomes of carotid endarterectomy. J Vasc Surg 2004;39:372-380.

44 Sacco RL, Adams R, Albers G, Alberts MJ, Benavente O, Furie K, Goldstein LB, Gorelick P, Halperin J, Harbaugh R, Johnston SC, Katzan I, Kelly-Hayes M, Kenton EJ, Marks M, Schwamm LH, Tomsick T: Guidelines for prevention of stroke in patients with ischemic stroke or transient ischemic attack: a statement for healthcare professionals from the American Heart Association/American Stroke Association Council on Stroke. Cosponsored by the Council on Cardiovascular Radiology and Intervention. The American Academy of Neurology affirms the value of this guideline. Stroke 2006;37:577-617.

-45 Ting AC, Taylor DC, Salvian AJ, Chen JC, Strandberg S, Hsiang YN: Carotid endarterectomy in octogenerians. Cardiovasc Surg 2000;8:441-445.

46 Hoyert DL, Heron MP, Murphy SL, Kung HC: Deaths: final data for 2003. Natl Vital Stat Rep 2006;54:1-120. 